\title{
DEPÓSITOS DE QUARTZO AMETISTA EM MINAS GERAIS
}

\author{
Coralie H. Dias ${ }^{1}$, Mario L. S. C. Chaves ${ }^{1}$, Rosaline C. Figueiredo e Silva ${ }^{1}$
}

${ }^{1}$ Centro de Pesquisa Manoel Teixeira da Costa - Instituto de Geociências da UFMG - Avenida Antônio Carlos, 6627 - Campus Pampulha, Belo Horizonte - MG, CEP 31270-901(co.dias.minas@gmail.com; autor correpondente)

Recebido em 28 de fevereiro de 2019, aceito em 20 dezembro de 2019

Resumo: Em Minas Gerais, o quartzo ametista ocorre em diferentes ambientes geológicos de formação. O presente trabalho apresenta uma revisão do conhecimento acerca destas ocorrências e depósitos. Ametistas em cavidades de basaltos se restringem no Estado à região do Triângulo Mineiro. As cavidades preenchidas são presentes na porção superior do nível central de derrames, contendo, além de quartzo, minerais tipicamente formados em baixas temperaturas como argilominerais e calcita. Os depósitos em veios hidrotermais relacionam-se principalmente ao contexto geológico da Serra do Espinhaço e adjacências a leste e possuem provável idade Brasiliana, representando os maiores volumes em termos de produção e pesquisas relacionadas. Nestes, a ametista associa-se principalmente a quartzo hialino ou leitoso e óxidos de ferro. Em pegmatitos, a ametista não é muito comum, embora existam informações de ocorrências próximas a Teófilo Otoni, além da ocorrência estudada em Pancas (ES). Estas situam-se no contexto da Província Pegmatítica Oriental do Brasil, relacionadas a pegmatitos não zonados e pouco diferenciados, contendo quartzo, feldspato e muscovita, além de apatita, crisoberilo e água-marinha.

Palavras-Chave: Ametista, Depósitos Minerais, Minas Gerais.

Abstract: : In Minas Gerais State, quartz amethyst occurs in different genetic geological environments. The present paper presents a review of the knowledge about such occurrences and deposits. Amethyst filling cavities in basalts, similar to those from southern Brazil, are restricted to Triângulo Mineiro region. Filled cavities are present at the upper portion of the central level of volcanic flows and contain, besides quartz, minerals typically formed at low temperatures such as clay minerals and calcite. Hydrothermal vein deposits are mainly related to the Espinhaço Mountain Range and vicinities to east, showing a probable Brasiliano age, and represent the largest volumes in terms of related production and researches. They show amethyst associated mostly to hyaline or milky quartz and iron oxides. In pegmatites, amethyst is not very common, although occurrences close to Teófilo Otoni are reported, besides the studied occurrence in Pancas (ES). This is situated within the context of the Eastern Brazilian Pegmatite Province, related to unzoned and little differentiated pegmatites which contain quartz, feldspar, muscovite, besides apatite, aquamarine and chrysoberyl.

Keywords: Amethyst, Mineral Deposits, Minas Gerais State

\section{INTRODUCÃO}

O Estado de Minas Gerais figura entre as maiores regiões produtoras de gemas e minerais industriais do país e do mundo. O quartzo é um dos minerais mais comuns e explorados possuindo aplicação tanto industrial como gemológica, além de interesse como mineral de coleção. Dentre suas diversas variedades coloridas, a ametista é uma das mais apreciadas pelos comerciantes e fabricantes de jóias, além de atrair o interesse do mercado de esoterismo.

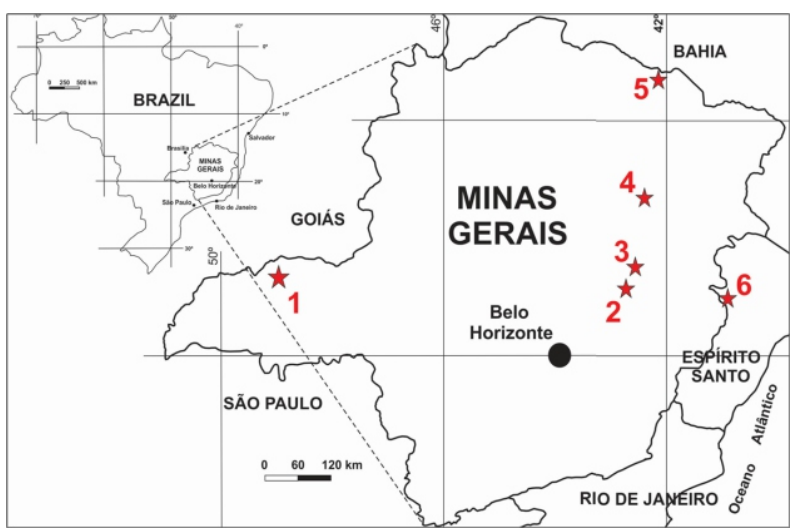

Figura 1 - Mapa de Minas Gerais e adjacências, mostrando a localização aproximada dos depósitos/ocorrências descritos neste trabalho. 1- Tupaciguara, 2- Felício dos Santos, 3- Buenópolis, 4- Grão Mogol, 5-Montezuma, 6-Pancas (ES).
Nesse Estado, a ametista ocorre em vários ambientes geológicos distintos: em cavidades de basaltos; em veios de quartzo hidrotermal; em pegmatitos graníticos; e ainda em depósitos secundários aluvionares e coluvionares. No entanto, os depósitos em veios hidrotermais da Serra do Espinhaço e, principalmente, suas adjacências a leste, são responsáveis pela maior quantidade de ocorrências e pesquisas científicas. Ametistas em pegmatitos graníticos são raras, e ocorrências em cavidades de basaltos e depósitos aluvionares e coluvionares também são incomuns, praticamente inexistindo relatos sobre elas.

No mercado gemológico, são comuns as práticas de irradiação e tratamento térmico de pedras com o intuito de modificar ou melhorar sua cor, agregando assim valor às gemas. Ambas as práticas fornecem resultados diferentes em função da presença de diversas impurezas na estrutura do mineral tratado, que parece ter relação com seu ambiente e condições de formação.

O presente trabalho tem por objetivo descrever e comparar os principais aspectos geológicos e mineralógicos de depósitos e ocorrências de ametista conhecidos em cada um desses ambientes de formação no Estado de Minas Gerais (excetuando o depósito descrito no ambiente pegmatítico, situado no Espírito Santo na proximidade com a fronteira mineira), a partir de informações disponíveis na literatura e obtidas em trabalhos de campo realizados no âmbito do desenvolvimento da tese de doutorado da primeira autora. 


\section{METODOLOGIA}

Este estudo consistiu inicialmente da etapa de revisão bibliográfica, em que foram adquiridos materiais como artigos, dissertações e teses abordando a geologia e mineralogia dos depósitos de ametista nos diferentes ambientes geológicos. Em seguida, uma segunda etapa envolveu a realização de trabalhos de campo para visita aos locais abordados, descrição geológica e registro fotográfico, além de coleta de amostras para futuros trabalhos analíticos.

\section{RESULTADOS}

Segundo Delaney (1996), as variedades gemológicas do quartzo, dentre elas a ametista, podem ser encontradas numa grande variedade de ambientes geológicos e rochas hospedeiras. Os mais comuns são: vulcânico, em cavidades preenchidas, ou geodos; veios, principalmente hidrotermais; granito-pegmatítico, em veios ou núcleos de pegmatitos; e aluvionar/coluvionar, em cascalhos aluviais, coluviais e stonelines.

Neste estudo serão enfocados depósitos e ocorrências minerais dos quatro tipos de ambientes presentes em Minas Gerais e adjacências (Figura 1).

\section{Ambiente vulcânico}

Segundo Delaney (1996), as ametistas mais importantes e de melhor qualidade gemológica são aquelas derivadas de cavidades (geodos) em basaltos. Cerca de $80 \%$ da produção brasileira é derivada dos depósitos nessas rochas no Rio Grande do Sul, associadas a derrames vulcânicos da Bacia do Paraná. Tais derrames podem atingir a espessura máxima de $1.700 \mathrm{~m}$, cobrindo uma área aproximada de $917.000 \mathrm{~km}^{2}$ no Brasil, Uruguai, Paraguai e Argentina (Piccirillo \& Melfi, 1988; Frank et al., 2009).

Em Minas Gerais, ocorrem exclusivamente na região do Triângulo Mineiro, onde existem algumas poucas referências a depósitos de ametista (ou de ágata), todas elas fazendo breves menções (e.g. Leonardos, 1956; Mattos, 1974; Favacho-Silva, 2000). Recentemente, Dias et al. (2019) descreveram as ocorrências de Tupaciguara (Figura 1), Ituiutaba e Nova Ponte.

As rochas vulcânicas em questão foram designadas como Formação Serra Geral - Grupo São Bento por Gordon Jr. (1947), termo largamente difundido na literatura. A origem destes derrames relaciona-se à atividade vulcânica ocorrida na plataforma Sul Americana, associada à abertura da porção sul do Oceano Atlântico, com idades em torno de 134,7 \pm 1 Ma (e.g., Thiede \& Vasconcelos, 2010; Dodd et al., 2015). Em Minas Gerais, poucas informações estão disponíveis sobre esse evento (e.g., Barbosa et al., 1970; Sgarbi, 1997), além de inexistirem dados geocronológicos a respeito.

Dias et al. (2019) descreveram três depósitos com características ligeiramente distintas no ambiente vulcânico em Minas Gerais (Figura 2): Fazenda Barreiro (município de Tupaciguara), Pedreira Incopol (município de Ituiutaba) e localidade de Tembezinho (município de Nova Ponte), abordando sua geologia e mineralogia, além de compará-los aos seus congêneres que ocorrem nos derrames basálticos do Rio Grande do Sul e Uruguai. Nas áreas enfocadas, os litotipos do vulcanismo Serra Geral são sobrepostos por depósitos sedimentares continentais do Grupo Bauru.

De maneira geral, tais depósitos são tipicamente gerados na porção superior do nível central dos derrames de lavas do vulcanismo Serra Geral, onde cavidades podem ser preenchidas por ametista e/ou outras variedades de quartzo como calcedônia, ágata e quartzo hialino, além de zeólitas, opala, calcita, gipsita, e mais raramente barita (Juchem et al., 1990; Juchem, 2013).

\section{Fazenda Barreiro}

Entre as ocorrências de ametista visitadas na região do Triângulo Mineiro, a única explorada economicamente, através de Permissão de Lavra Garimpeira, é a da Fazenda Barreiro. O depósito está localizado no município de Tupaciguara, nas proximidades da rodovia BR-452 (GPSUTM 708060E e 7951970N, 22K). No local, segundo informações do proprietário da fazenda, a extração de cristais de ametista se dá desde 2011.

A mineralização ocorre a oeste da sede da fazenda em um regolito oriundo da alteração do basalto, com cerca de 3$5 \mathrm{~m}$ de espessura (Figura 3). A ametista neste depósito é encontrada principalmente em geodos esféricos a semiesféricos, às vezes um pouco alongados num dos eixos, exibindo formato cônico, de portes centimétricos a decimétricos. Individualmente, os cristais possuem formato alongado, são subédricos, com a terminação mais larga que a base e zonamento da cor, sendo em geral mais intensa do centro para a terminação da pirâmide dos cristais. Em termos mineralógicos e cristalográficos ressalta-se a semelhança com as ametistas de geodos do Rio Grande do Sul.

O nível basal do depósito encontra-se exposto a nordeste, em cortes nas margens da rodovia (GPS-UTM 708680 e e 7952508N, 22K). Em termos petrográficos, o basalto é hipocristalino, de textura ofítica a subofítica, composto principalmente por plagioclásio, clinopiroxênio e vidro vulcânico, além de minerais opacos, sendo que tais minerais encontram-se praticamente inalterados. A rocha hospedeira do nível mineralizado, situado cerca de $50 \mathrm{~m}$ acima do corte da estrada, é também um basalto hipocristalino, porém com mais vesículas e amígdalas (preenchidas por argilominerais). É petrograficamente similar ao nível inferior, além de possuir minerais secundários decorrentes de alteração hidrotermal de baixa temperatura, como óxidos/hidróxidos de ferro e esmectita (comprovada por difração de raios $\mathrm{X}$ ) preenchendo cavidades ou interstícios da matriz.

\section{Ambiente hidrotermal}

As maiores jazidas de veios hidrotermais de quartzo colorido em Minas Gerais se localizam na Serra do Espinhaço e adjacências a leste, inseridas principalmente em filitos e quartzitos do Supergrupo Espinhaço e do Grupo Macaúbas. 


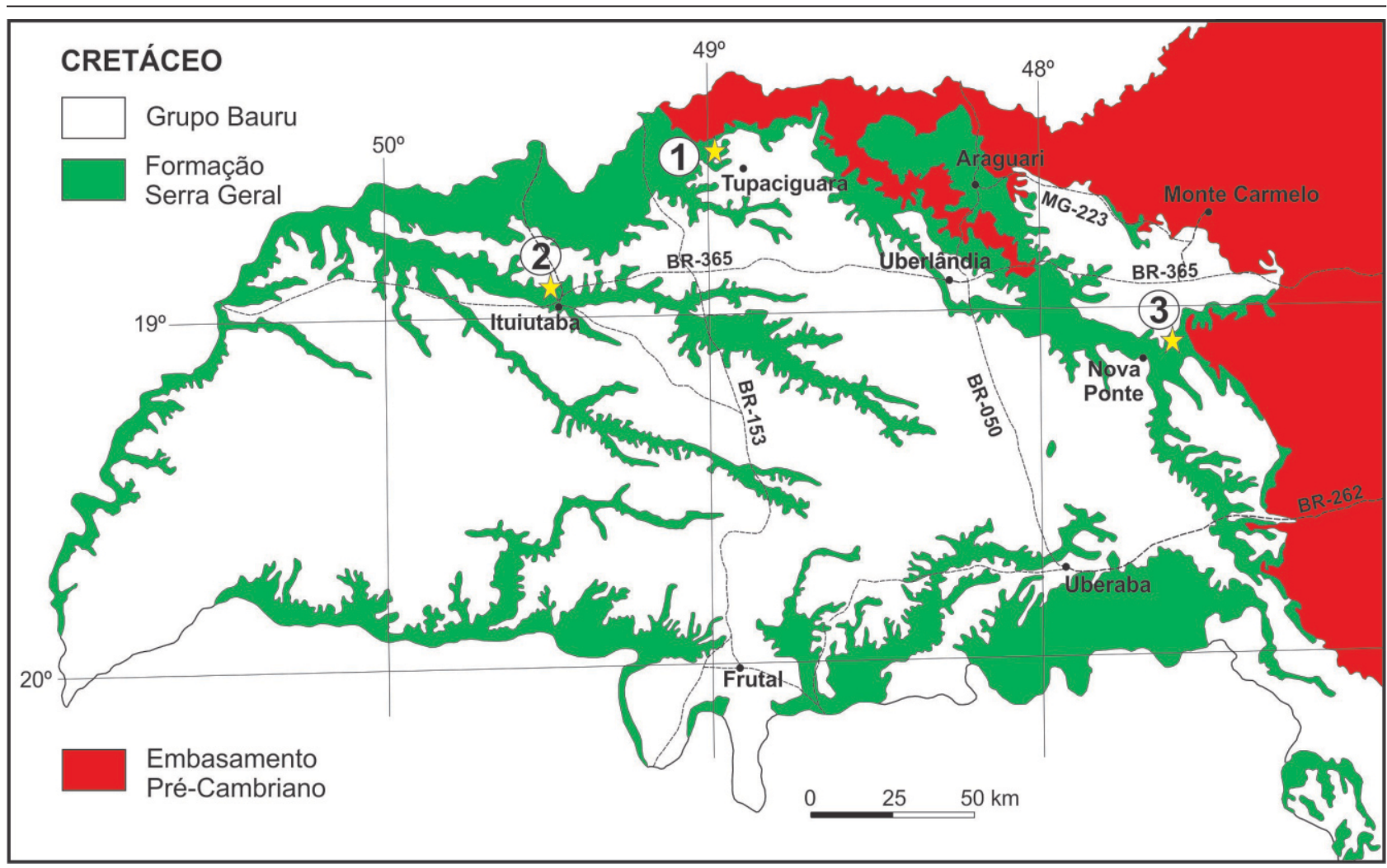

Figura 2-Geologia simplificada da região do Triângulo Mineiro (modificado de Pinto \& Silva, 2014), ressaltando a distribuição do vulcanismo Serra Geral com a localização das ocorrências de ametista descritas em Dias et al. (2019). 1: Fazenda Barreiro (Tupaciguara); 2: Pedreira Incopol (Ituiutaba); 3: Tembezinho (Nova Ponte).

São veios de dimensões métricas até quilométricas que ocorrem praticamente em toda a região e que se encontram condicionados principalmente a falhas inversas de alto ângulo. Os veios mais potentes em geral são maciços possuindo pequenas porções no núcleo onde ocorre a cristalização (Carvalho, 1982). Os de menor porte podem ser tanto maciços como cristalizados, como ocorre no caso dos depósitos de ametista (Chaves \& Coutinho, 1992).

Carvalho (1982) propôs um modelo simples para o desenvolvimento dos veios de quartzo na Serra do Espinhaço, em que fluidos hidrotermais ascendentes, aquecidos e saturados em sílica, precipitam seu conteúdo devido à diminuição da temperatura em direção aos níveis crustais superiores, tornando a solução supersaturada em sílica. Deste modo, veios irregulares, de tamanhos variados, sem cristalinidade e bastante leitosos, são gerados em zonas de baixa solubilidade de sílica, onde a temperatura não ultrapassa $200-300^{\circ} \mathrm{C}$. Em níveis crustais inferiores, em temperaturas em torno de $400^{\circ} \mathrm{C}$ e onde possivelmente a solubilidade de sílica é maior, os veios gerados possuem mais regularidade e facilidade de migração devido a este aumento de solubilidade, formando veios de comprimentos superiores a $1 \mathrm{~km}$ (Carvalho, 1982).

Com relação à origem destes veios, o processo hidrotermal está relacionado ao metamorfismo regional de idade Brasiliana que afetou as unidades geológicas presentes na Serra do Espinhaço e adjacências; sua geração principal foi datada em cerca de $490 \mathrm{Ma}$ (Chaves et al., 2010; Chaves et al., 2018; U-Pb em monazita e xenotima, respectivamente).
Os três principais depósitos conhecidos neste ambiente são os de Montezuma, Felício dos Santos e Grão Mogol, descritos a seguir. Existem ainda outros depósitos pouco conhecidos, como o da Serra do Pinho (Alvinópolis), na porção terminal sul da Serra do Espinhaço (Supergrupo Espinhaço), e o de Itamarandiba, associado ao Grupo Macaúbas.

\section{Montezuma}

É uma lavra bastante antiga e ainda importante, primeiramente descrita por Moraes (1936). Este autor denominou tal lavra de "Anta Gorda", estando situada na Fazenda Tábua, nas proximidades do vilarejo de Água Quente (GPS-UTM 771517E e 8322349N, 23L), que atualmente corresponde à sede do município de Montezuma. Àquela época, a localidade pertencia ao município de Rio Pardo de Minas.

A geologia desta área é alvo de controvérsias. Bruni \& Schobbenhaus Filho (1976) consideraram os quartzitos encaixantes dos veios mineralizados como pertencentes ao Supergrupo Espinhaço (Paleo-Mesopreterozoico). No entanto, mapeamento geológico de Knauer et al. (2015) considerou tais rochas como pertencentes ao Grupo Serra de Inhaúma (Neoproterozoico), embora estes autores não tenham mencionado o depósito em questão. Conforme diversos autores (e.g., Bruni \& Schobbenhaus Filho, 1976; Cassedanne \& Cassedanne, 1975, 1976, 1977), a ametista ocorre relacionada a um enxame principal de veios de quartzo, de possança entre decímetros até $2 \mathrm{~m}$ de espessura, e ainda em vários veios menores interconectados com o principal, os quais preenchem uma zona de falha na encaixante. 
Segundo Cassedanne \& Cassedanne (1975) a linha principal de veio tem direção $\mathrm{N} 45^{\circ} \mathrm{W} / 70^{\circ} \mathrm{SW}$ até subvertical. Conforme Imagem Google recente da zona de mineralização (Figura 4-A) observa-se nitidamente que os veios se associam a uma zona de charneira NE-SW de uma dobra fechada a isoclinal, rompida a leste.

Os veios são atapetados de cristais de ametista de cor roxa forte, de tamanho variado, podendo alcançar $20 \mathrm{~cm}$ nas drusas. Apresenta sempre zonas de crescimento repetidas, e somente as extremidades são aproveitadas. Localmente, argila branca pode preencher as cavidades nos veios, assim como brechas cimentadas com calcedônia. Ainda segundo Cassedanne \& Cassedanne (1975), os vários veios se caracterizam por conterem somente um tipo de cristal, ou com três ou com seis faces na pirâmide terminal. Atualmente paralisada, a mineração era feita pela Mineração Badin Ltda. através de uma galeria com $180 \mathrm{~m}$ de comprimento (Figura 4-B), que produzia por mês cerca de $900-1000 \mathrm{~kg}$ de material de primeira qualidade, selecionado manualmente.

Sob aquecimento em cerca de $550^{\circ} \mathrm{C}$, tal material tem a característica de adquirir uma tonalidade verde oliva diferenciada das demais cores naturais do quartzo (Figuras 4-C e 4-D), conhecido como prasiolita no mercado gemológico (Schumann, 1995), uma das poucas localidades em que se sabe que tal fenômeno ocorre. Com a mineração em questão paralisada, a prasiolita disponível atualmente é originada de tratamento com radiação gama. Segundo Hebert \& Rossman (2008), a cor da prasiolita não é decorrente simplesmente de aquecimento ou exposição ao sol, sendo resultado de mudanças químicas e térmicas na solução que precipitou o mineral.

\section{Felício dos Santos}

Chaves \& Coutinho (1992) foram os primeiros a descreverem tal depósito. Segundo esses autores, entre as décadas de 1940 e 1980, duas zonas principais de ocorrências na Fazenda Sobrado produziram amostras para lapidação e coleção (Figura 5-A). O depósito, também conhecido como Lavra da Pedra Roxa, está localizado cerca de $7 \mathrm{~km}$ a sudeste de Felício dos Santos (centroide em GPS-UTM 692039E e 7997949N, 23K). Recentemente (2017) verificou-se uma tentativa de retomada dos serviços, embora de modo intermitente (Figura 5-B).

O depósito da Fazenda Sobrado está situado no flanco ocidental da Serra Negra, a qual constitui uma extensão a leste da Serra do Espinhaço. Na área, ocorrem inúmeros veios contendo ametista que cortam as rochas regionais, que correspondem a mica-quartzo xistos, atribuídos inicialmente de modo informal à "Sequência Serra Negra" conforme Uhlein (1987). Tupinambá et al. (1996) redefiniram tais rochas como pertencentes à Formação Capelinha, topo do Grupo Macaúbas.

A mineralização de ametista se dá em corpos lenticulares de alguns decímetros até alguns metros de comprimento, compostos por quartzo leitoso e algumas drusas atapetadas de cristais, que podem ser de quartzo leitoso, hialino ou morion claro, e atingir 30 $\mathrm{cm}$ de comprimento. Segundo Chaves \& Coutinho (1992), as lentes são em geral paralelas à xistosidade da rocha encaixante, de atitude $\mathrm{N} 40^{\circ} \mathrm{E} / 20^{\circ} \mathrm{NW}$. A ametista ocorre comumente associada a caulim, crescendo sobre quartzo incolor ou leitoso com hematita, e tendo a extremidade superior dos cristais sempre mais corada.

\section{Grão Mogol}

No início da década de 1970 foram descobertas duas pequenas ocorrências de ametista bem próximas, na Fazenda Riacho do Barreiro, região de Grão Mogol, que forneceram desde então de modo esporádico material para lapidação e principalmente drusas para coleção. A última tentativa de lavra foi feita em meados de 1998. Essa fazenda está localizada a cerca de $15 \mathrm{~km}$ a norte da cidade, na borda oeste da Serra do Espinhaço enquanto os veios com ametista situam-se no próprio espigão serrano (Figura 6-A; GPS-UTM 725286E e 8183248N, 23K).

A geologia de tal região foi levantada por Chaves et al. (1999), que observaram neste trecho serrano quartzito fino, laminado, pertencente à Formação Resplandecente (Supergrupo Espinhaço), onde o acamamento paralelo à xistosidade orienta-se na direção $\mathrm{N} 10-30^{\circ} \mathrm{E} / 55-70^{\circ} \mathrm{SE}$, com sistemas de fraturas superimpostos segundo W-E e NW-SE. O veio "superior" (cota 950m) possui espessura variável entre $10-30 \mathrm{~cm}$, orientado $\mathrm{W}-\mathrm{E} / 75^{\circ} \mathrm{N}$, concordante ao padrão de fratura local; os cristais de ametista neste local são normalmente mal formados e menores que $5 \mathrm{~cm}$ de comprimento, agregando-se uns aos outros irregularmente.

No depósito "inferior" (cota $900 \mathrm{~m}$ ) o veio possui espessura maior $(0,5-1,0 \mathrm{~m})$, estando orientado $\mathrm{N} 30^{\circ} \mathrm{W} / 70^{\circ} \mathrm{SW}$, subparalelamente ao padrão de fraturas. Neste local, porém, podem ser observadas drusas mais bem formadas, preenchendo bolsões no veio de quartzo hialino (Figura 6-B), com cristais terminados nas faces piramidais, alcançando até cerca de $30 \mathrm{~cm}$ de base. A maior parte das cerca de 2 toneladas de material produzido na região são provenientes deste veio inferior. A coloração roxa é bem distribuída ao longo do cristal na maior parte dos espécimes observados, fato incomum nessa variedade, onde a coloração em geral concentra-se no vértice das pirâmides. No entanto, em termos econômicos, a ametista de Grão Mogol tem seu potencial bastante limitado (para lapidação), uma vez que a coloração roxa é perdida após alguns dias de exposição solar (Karfunkel et al., 1998).

\section{Ambiente pegmatítico}

O maior volume de quartzo encontrado na Província Pegmatítica Oriental do Brasil associa-se ao núcleo dos corpos pegmatíticos. A ametista não é muito comum neste ambiente geológico, porém segundo Favacho-Silva (2000) ela ocorre principalmente em alguns corpos nas proximidades de Teófilo Otoni, não sendo fornecidas suas localizações, e em Pancas (ES), apresentando uma coloração roxa escura incomum. 


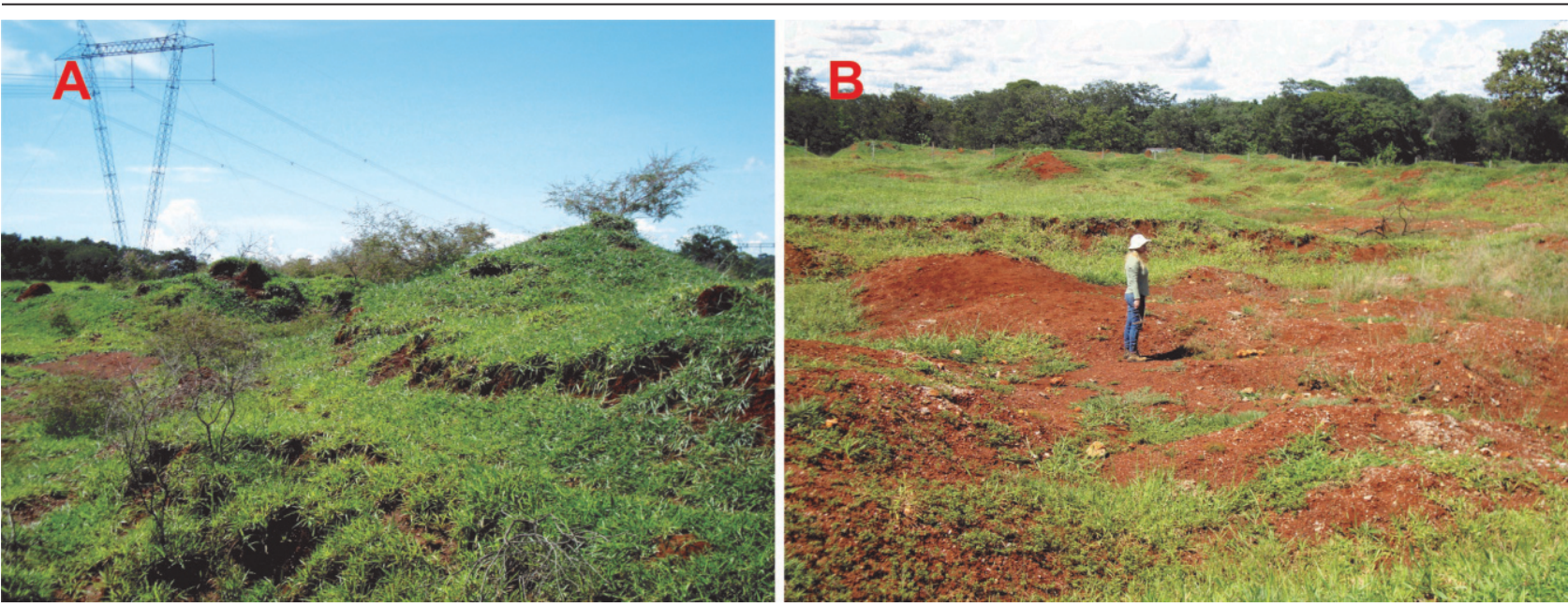

Foto 3 -A - Aspecto geral do regolito basáltico que hospeda a mineralização da Fazenda Barreiro. B-Detalhe das escavações desenvolvidas nas partes mais intemperizadas do depósito.
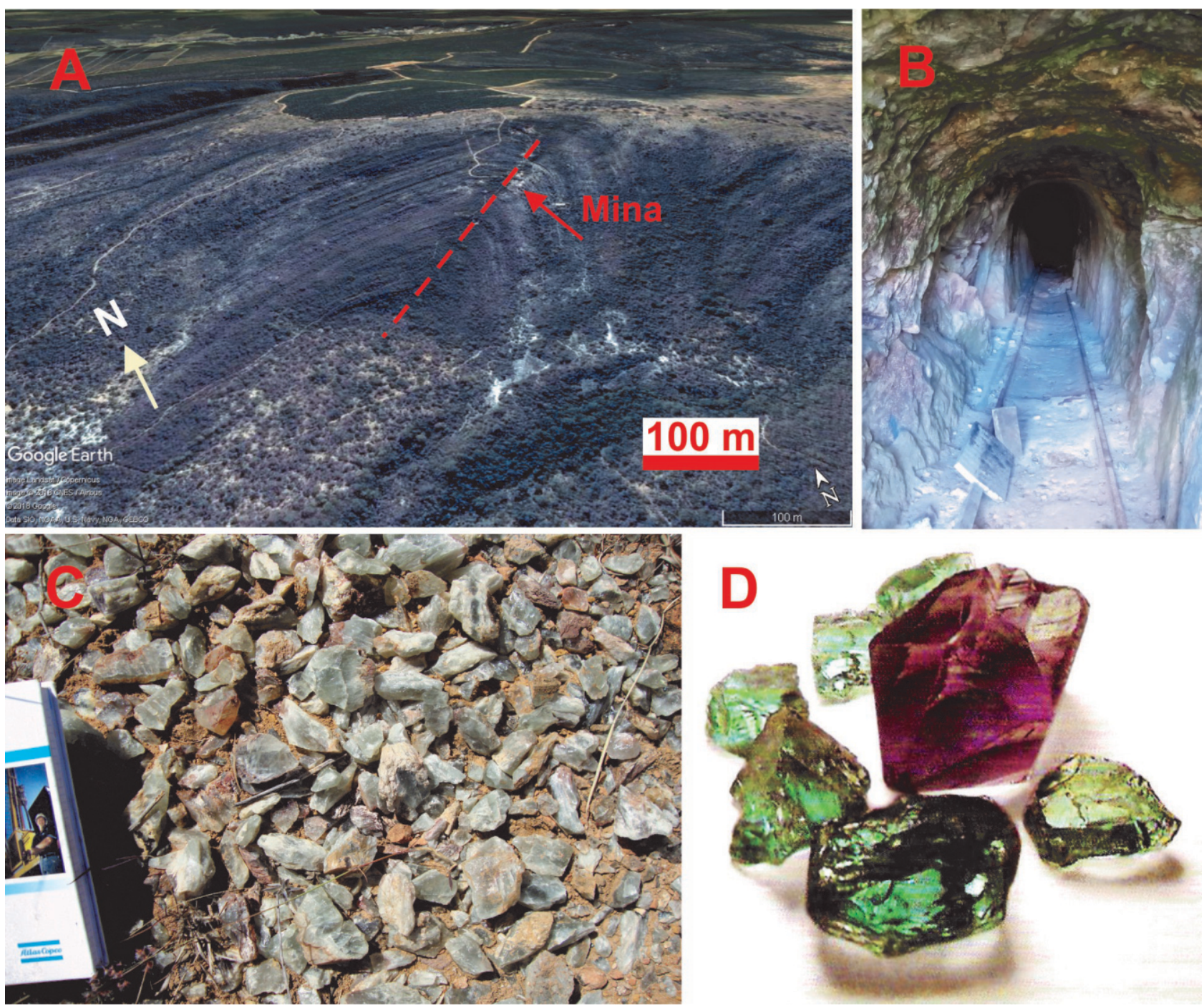

Figura 4-A-Imagem Google da dobra fechada a isoclinal que provavelmente controla o depósito de ametista de Montezuma, onde a mineralização ocorre no plano axial da mesma. B - Vista da entrada da galeria principal da mina. C - Material de rejeito de coloração esverdeada. D-Ametista de Montezuma (ao centro) transformada em prasiolita pelo aquecimento em cerca de $550^{\circ} \mathrm{C}$ (conforme Schultz-Güttler, 2007). 
Os pegmatitos são oriundos de frações residuais do magma, formadas a partir do fracionamento magmático, ou ainda de atividade hidrotermal tardi-magmática, por mistura de fluidos quimicamente distintos. Tais processos levam ao enriquecimento do fluido em elementos incompatíveis, substâncias voláteis e metais raros ( $\mathrm{Be}, \mathrm{Nb}, \mathrm{Ta}, \mathrm{Li}, \mathrm{Rb}, \mathrm{Ce}$ e $\mathrm{Ga}$ ), refletindo na mineralogia única dos pegmatitos, como a presença de gemas, minerais raros e minerais industriais, o que leva à exploração econômica desta rocha.

Devido à mineralogia presente, os pegmatitos podem ser não zonados ou zonados. Os não zonados, também denominados homogêneos, são constituídos majoritariamente por quartzo, feldspato potássico e mica, essencialmente muscovita, e os minerais distribuem-se de forma regular ao longo do corpo, em cristais que variam de centimétricos a decimétricos. No entanto, podem apresentar turmalina, apatita, berilo, granada e topázio como minerais acessórios (e.g., London, 2008). Em pegmatitos que apresentam zonamento, este pode se dar quanto à distribuição de tamanho dos cristais, quanto à assembleia mineral ou ainda textura da rocha, e é geralmente dividido nas seguintes zonas: marginal ou de borda, sendo a zona mais externa e que mostra transição com a rocha encaixante, é constituída essencialmente por quartzo, feldspato e grandes placas de muscovita, podendo ainda haver presença de cassiterita e granada; zona mural ou de parede, que assemelha-se a um pegmatito homogêneo em sua granulação, composição e estrutura, ocupando o maior volume do corpo e passando gradativamente para a zona intermediária, que se destaca pela presença de minerais de minério como ambligonita, berilo, columbita-tantalita, espodumênio, dentre outros, além de feldspatos em cristais gigantes; por fim a zona axial ou núcleo é constituída por um núcleo de quartzo maciço, de cores variadas, de forma regular, irregular ou disseminado em grandes blocos, dispostos simetricamente ou não em relação às outras zonas. Os corpos de substituição são unidades formadas primariamente por substituição de pegmatito
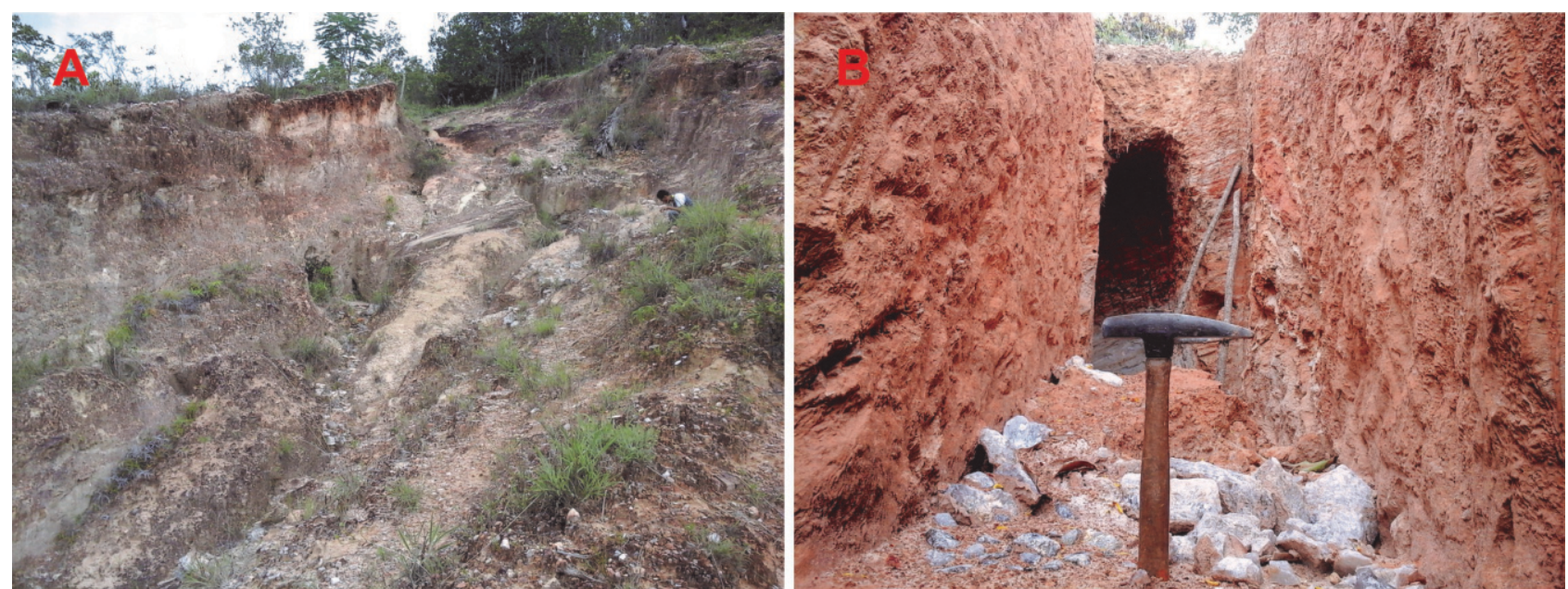

Figura 5 - Vistas parciais da ocorrência da Fazenda Sobrado. A - Área de lavra mais antiga, abandonada. B - Escavações recentes com fragmentos de quartzo leitoso e hialino em meio ao xisto encaixante intensamente alterado. 
Desde meados da década de 1990 essa área vem produzindo grande quantidade de quartzo hialino ou levemente arroxeado ou esverdeado (centroide em GPSUTM 619452E e 8033396N, 23K).

Tal depósito foi brevemente descrito por Chaves \& Favacho-Silva (2000), e as cascalheiras arenosas onde a ametista foi descrita associam-se, conforme Noce \& Fogaça (1997), a uma zona de afloramentos da Formação Galho do Miguel do Supergrupo Espinhaço (PaleoMesoproterozoico), próximo ao contato com metadiamictitos do Grupo Macaúbas (Neoproterozoico). A cascalheira coluvionar em lavra é rica em fragmentos angulosos de quartzo e quartzito, ocupando um vale de direção aproximada N-S (Figuras 8-A e 8-B). Possui espessura média em torno de $30-40 \mathrm{~cm}$, embora possa alcançar até $2 \mathrm{~m}$, ou mesmo estar totalmente ausente (Chaves \& Favacho-Silva, 2000; Favacho-Silva, 2000). diferentes ambientes de formação. As ametistas que ocorrem em geodos nos basaltos da Formação Serra Geral, coletadas na região do Triângulo Mineiro, apresentam cor mais fraca que nos outros ambientes de formação, e seus depósitos ou ocorrências mostram extensões bem mais limitadas e restritas do que nos renomados depósitos do sul do país.

O ambiente hidrotermal se destaca como o mais importante para a produção de ametistas em Minas Gerais. Tais depósitos representam não somente os maiores volumes em termos de produção, mas também de pesquisas científicas relacionadas (e.g., Moraes, 1936; Bruni \& Schobbenhaus Filho, 1976; Cassedanne \& Cassedanne, 1975, 1976, 1977; Chaves \& Coutinho, 1992; Karfunkel et al., 1998). Destacam-se nesse contexto os veios encaixados em quartzitos e xistos do Grupo Macaúbas (Neoproterozoico), que ocorrem
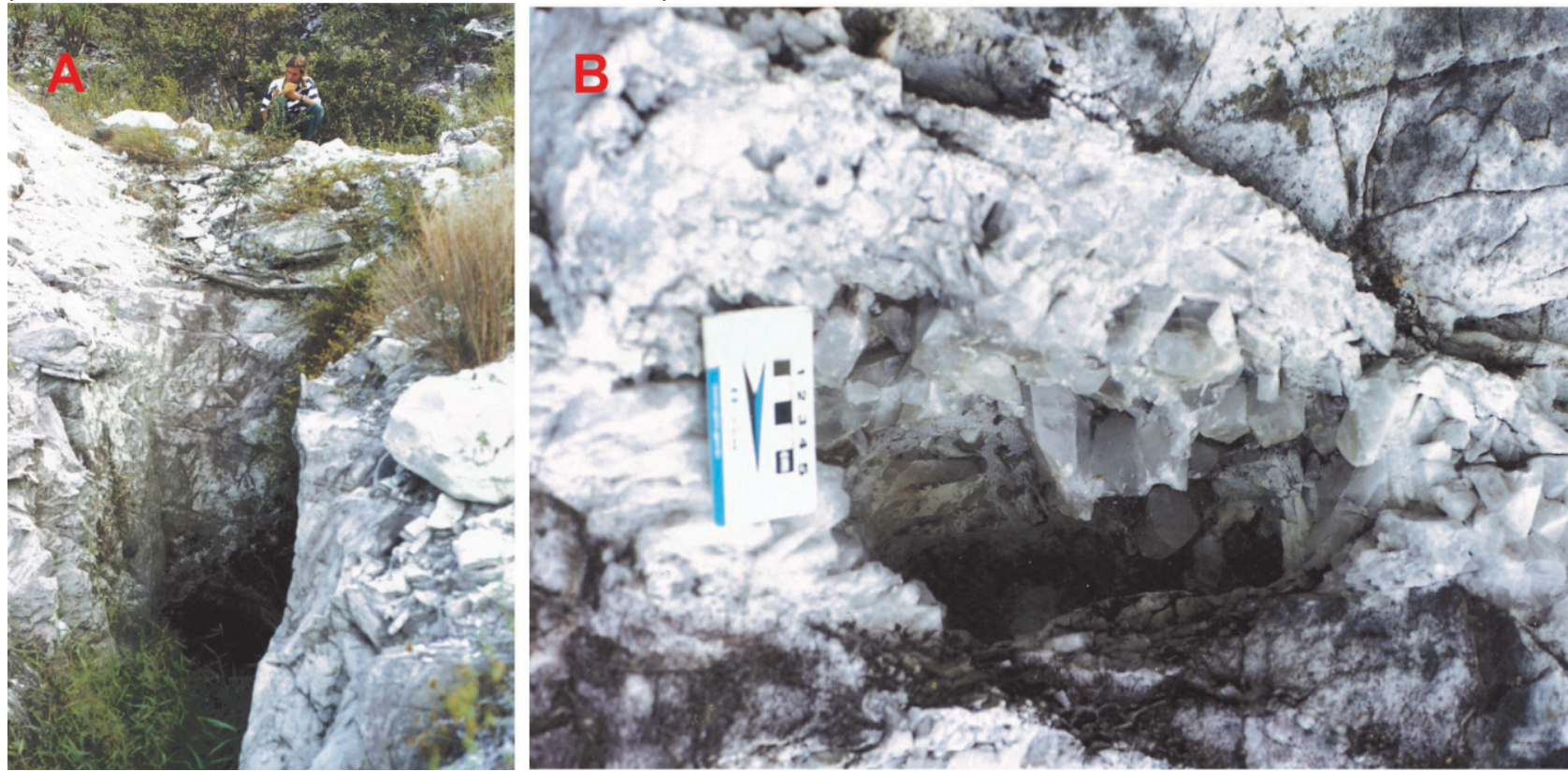

Figura 6 - A - Vista parcial da entrada da escavação no depósito da Fazenda Riacho do Barreiro. B - Porção de veio de quartzo hialino com cristais euédricos.

A maior parte dos clastos de quartzo aproveitáveis economicamente situam-se na faixa entre $1-3 \mathrm{~cm}$ de comprimento, sendo subangulosos a subarredondados. Embora a maioria destes clastos sejam incolores, segundo Pinheiro (1999) tal material adquire coloração violeta forte após irradiação com raios gama.

De acordo com o Sr. Mikio Takada, então dono da lavra, no período entre 1996-1997 o local chegou a produzir cerca de $10 \mathrm{~kg}$ por dia, e provavelmente cerca de 5 ton de material altamente lapidável já haviam sido extraídos (Chaves \& Favacho-Silva, 2000; Favacho-Silva, 2000). Aparentemente, o tamanho original dos clastos favorece a recuperação e posterior tratamento deste material.

\section{Discussões}

Depois do Rio Grande do Sul, Bahia e Minas Gerais, respectivamente, se destacam como os maiores produtores de ametista do Brasil, ocorrendo em serranias mais baixas, a leste do grande espigão montanhoso do Espinhaço.

serranias mais baixas, a leste do grande espigão montanhoso do As poucas amostras obtidas do ambiente pegmatítico (Pancas, ES) apresentaram cor mais intensa. Entretanto, tal variedade do quartzo parece ser bastante incomum na maior área de ocorrência de pegmatitos de Minas Gerais, a Província Pegmatítica Oriental do Brasil. Tanto neste ambiente quanto no ambiente hidrotermal a ametista é frequentemente encontrada com numerosas inclusões sólidas de hematita, que podem afetar o aproveitamento do material como gema. A presença de impurezas de ferro é relacionada à aquisição da cor violeta característica da ametista (e.g., Lehmann \& Moore, 1966; Dennen \& Puckett, 1972; Cohen \& Hassan, 1974; Cox, 1977; Cohen, 1985; Fischer et al, 1999; Dedushenko et al., 2004; Scholz et al., 2012), portanto a presença destas inclusões de hematita revelam o caráter enriquecido em ferro das soluções que precipitaram a ametista. 


\section{CONCLUSÃO}

Em cada um dos ambientes geológicos estudados, a ametista apresenta particularidades mineralógicas e geológicas. Em relação aos depósitos de classe mundial encontrados no Rio Grande do Sul e Uruguai, as amostras estudadas que mais se assemelham àquelas destes depósitos, em termos mineralógicos, são as do próprio ambiente vulcânico (Tupaciguara), entretanto, ametistas coletadas neste ambiente em Minas Gerais apresentam cor menos intensa, sendo as de pegmatito e veio hidrotermal as que possuem tonalidade violeta mais forte. Embora o ambiente vulcânico seja responsável por fornecer as maiores quantidades de ametistas e de melhor qualidade gemológica, com maior relevância em termos econômicos, os depósitos/ocorrências deste tipo genético em Minas Gerais apresentam potencial muito inferior aos famosos depósitos da região sul, ocorrendo exclusivamente na região do Triângulo Mineiro. Em contrapartida, as amostras gemológicas de destaque em Minas Gerais são provenientes do ambiente hidrotermal, fornecendo maior volume de amostras de coloração mais intensa e homogênea.
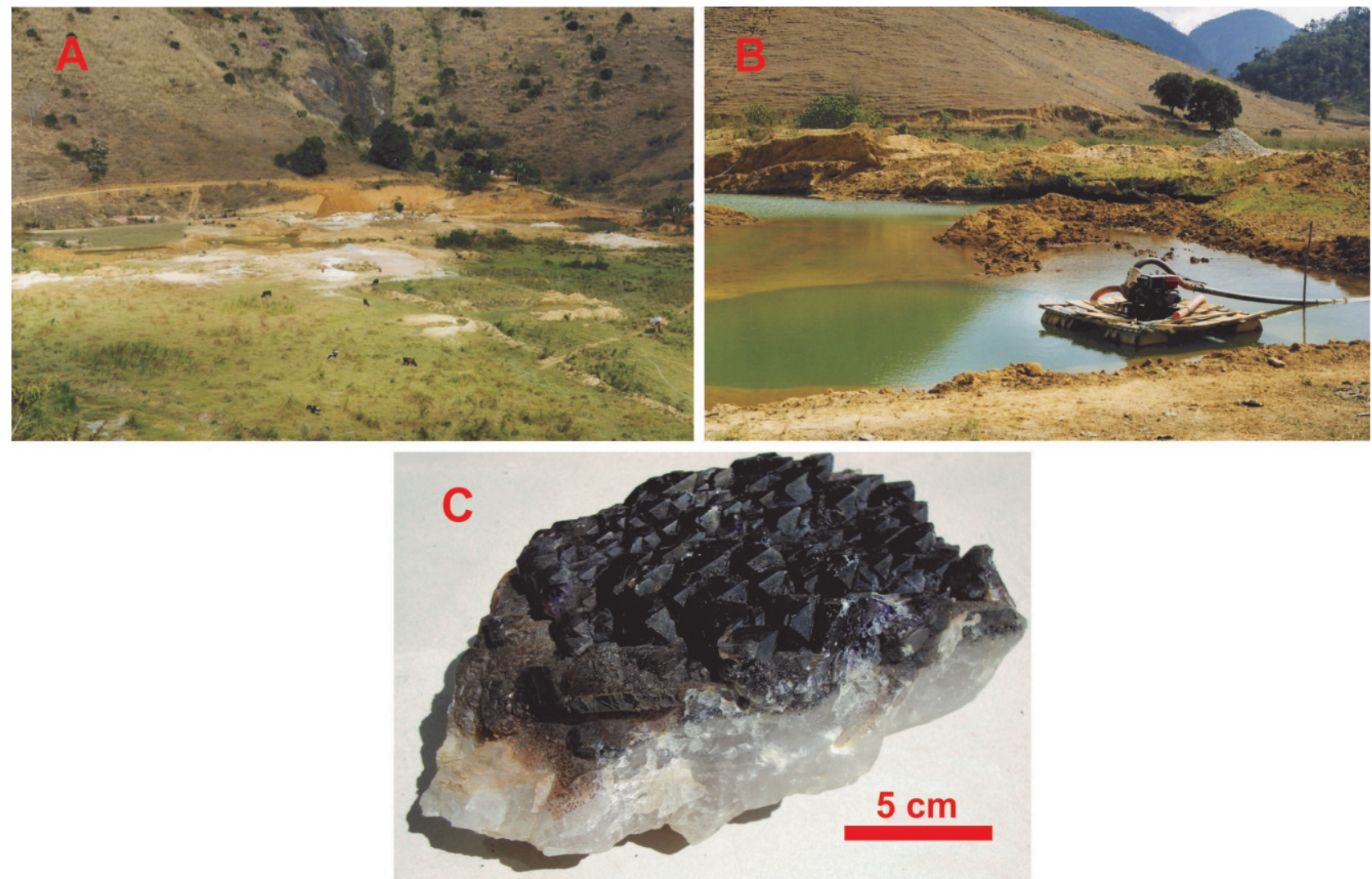

Figura 7-A - Vista geral da ocorrência de Pancas, em área rebaixada entre as intrusões graníticas. B-Área de dragagem de depósito aluvionar da região de Pancas. C-Amostra coletada na região de Pancas, mostrando a base de quartzo hialino e as extremidades terminadas em ametista de cor roxa intensa.

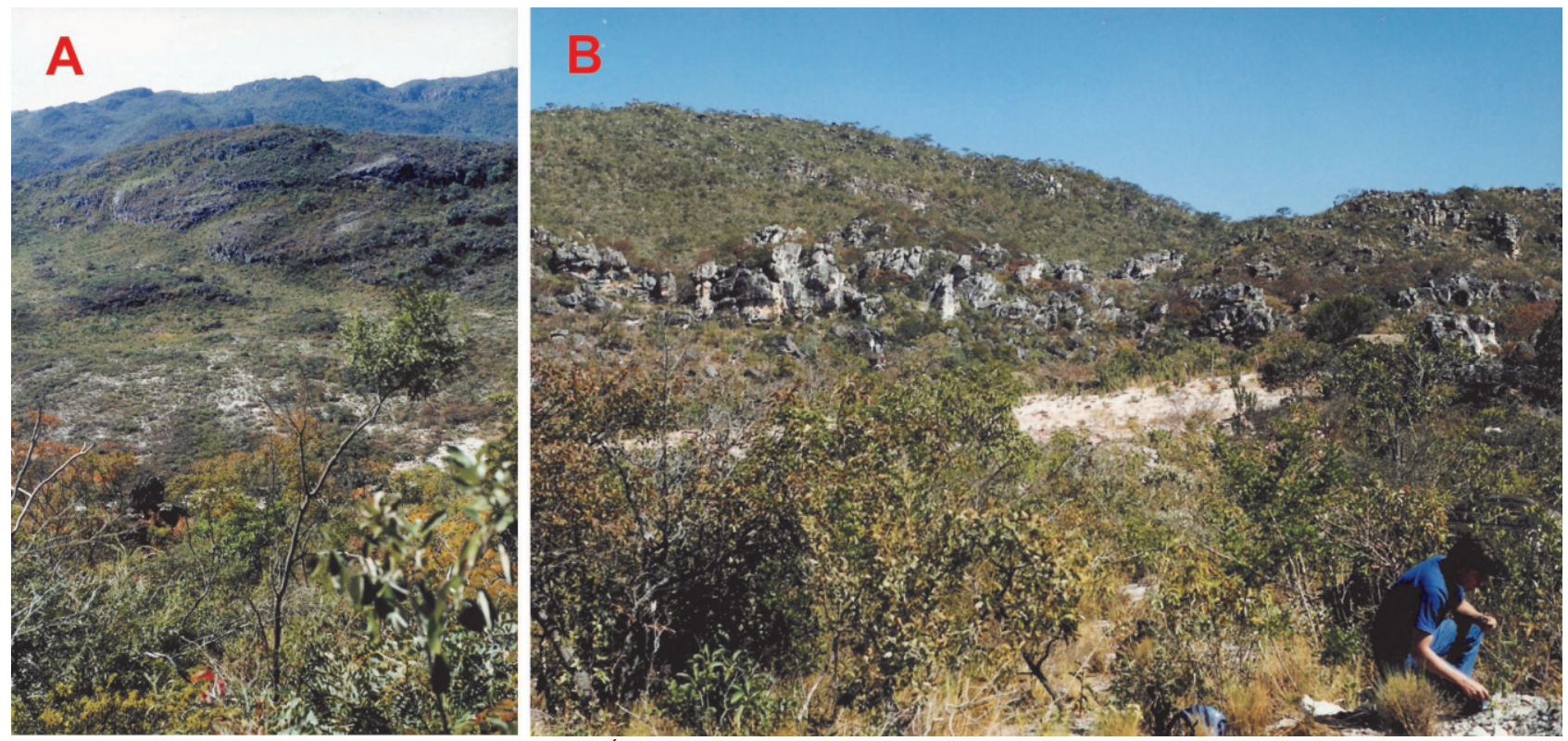

Figura 8-A-Vista geral do depósito da Fazenda Rainha. B - Área de extração na cascalheira coluvionar. 


\section{AGRADECIMENTOS}

O presente trabalho foi realizado com apoio da Coordenação de Aperfeiçoamento de Pessoal de Nível Superior - Brasil (CAPES) - Código de Financiamento 001, através de concessão de bolsa de doutorado à autora $C$. H. D. Agradecemos também ao Centro de Pesquisa Professor Manoel Teixeira da Costa (CPMTC-IGC/UFMG).

\section{REFERÊNCIAS BIBLIOGRÁFICAS}

Barbosa O., Braun O.P.G., Dyer R.C., Cunha C.A.B.R. 1970. Geologia da região do Triângulo Mineiro. Rio de Janeiro, DNPM/DFPM, Boletim 136, 140 p.

Bruni M.A.L., Schobbenhaus Filho C. 1976. Carta Geológica do Brasil ao Minionésimo, Folha Brasília. Brasília, DNPM, Texto Explicativo, $162 \mathrm{p}$.

Carvalho A.S. 1982. Geologia e gênese das mineralizações de quartzo no Espinhaço Meridional, Minas Gerais - Brasil. Dissertação de Mestrado, Departamento de Geociências, Universidade de Brasília, $94 \mathrm{p}$.

Cassedanne J.P. \& Cassedanne, J.O. 1975. As jazidas brasileiras de ametista. In: Cong. Ibero-Americano de Geol. Econ., 2, Tomo Il-4, p.183-194.

Cassedanne J.P \& Cassedanne J.O. 1976. Quelques gîtes d'améthyste à l'ouest de Vitória da Conquista (Brésil). Rev. Gemmologie, 47:6-9.

Cassedanne J.P. \& Cassedanne J.O. 1977. Axinite, hydromagnesite, amethyst and other minerals from near Vitória da Conquista (Brazil). Mineral. Rec., 8:382-387.

Chaves M.L.S.C. \& Coutinho D.C. 1992. Nota sobre a jazida de ametista da Fazenda Sobrado (Felício dos Santos - MG). REM-Rev. Esc. Minas, 45:194-195.

Chaves M.L.S.C., Karfunkel J., Addad J. 1999. Geologia da região diamantífera de Grão Mogol (MG). Geociências, 18:129-155.

Chaves M.L.S.C. \& Favacho-Silva M.D. 2000. Ocorrências singulares de quartzo gemológico (ametista, fumé e citrino) na Serra do Espinhaço, Minas Gerais. REMRev. Esc. Minas, 53:181-186.

Chaves M.L.S.C., Brandão P.R.G., Buhn B. 2010. Monazita em veios de quartzo da Serra do Espinhaço Meridional (MG): mineralogia, geocronologia e implicações geológicas. Rev. Bras. Geoc., 40:506-515.

Chaves M.L.S.C., Buhn B., Dias C.H., Menezes Filho L.A.D. 2018. Idades U-Pb em xenotímio-(Y) de um veio de quartzo com almeidaíta e parisita-(la), novos minerais encontrados na Serra do Espinhaço (Novo Horizonte, BA). Geociências, 37:225-236.

Cohen A.J. 1985. Amethyst color in quartz, the result of radiation protection involving iron. Am. Mineral., 70:1180-1185.

Cohen A.J. \& Hassan F. 1974. Ferrous and ferric ions in synthetic alpha-quartz and natu-ral amethyst. Am. Mineral., 59:719-728.

Cox R.T. 1977. Optical absorption of the $d 4$ ion Fe4+ in pleochroic amethyst quartz. J. Phys. C: S. St. Phys, 10:4631-4643.
Correia Neves J.M. 1981. Pegmatitos Graníticos: morfologia, mineralogia, geoquímica, gênese e metalogênese. Belo Horizonte, Universidade Federal de Minas Gerais, 500 p. Tese de concurso para professor titular.

Dedushenko S.K., Makhina I.B., Mar'in A.A., Mukhanov V.A., Perfiliev Y.U.D. 2004. What oxidation state of iron determines the amethyst colour? Hyperf. Int., 156/157:417-422.

Delaney P.J.V. 1996. Gemstones of Brazil: Geology and Ocurrences. Editora REM, Ouro Preto, 125 pp.

Dennen W.H. \& Puckett A.M. 1972. On the chemistry and color of amethyst. Can. Miner., 11:448-456.

Dias C.H., Chaves M.L.S.C., Juchem P.L., Romano A.W. 2019. Ocorrências de ametista em basaltos do Triângulo Mineiro (Minas Gerais): comparações com depósitos similares do Rio Grande do Sul. Pesq. Geoc., 46:e0822.

Dodd S.C., MacNiocaill C., Muxworthy A.R. 2015. Long duration ( $>4 \mathrm{Ma}$ ) and steady-state volcanic activity in the early Cretaceous Paraná-Etendeka Large Igneous Province: New paleomagnetic data from Namibia. Earth Planet. Sc. Lett., 414:16-29.

Favacho-Silva M.D. 2000. Variedades gemológicas de quartzo em Minas Gerais: geologia, gemologia, mineralogia, causas de cor, técnicas de tratamento e aspectos mercadológicos. Dissertação de Mestrado, Instituto de Geociências, Universidade Federal de Minas Gerais, $132 \mathrm{f}$.

Fischer A.C., Krambrock K., Pinheiro M.V.B., Juchem P.L. 1999. Natural and irradiated amethyst from Rio Grande do Sul studied by optical absorption and electron paramagnetic resonance. An. Acad. Bras. Ciênc., 71:823-824.

Frank H.T., Gomes M.E.B., Formoso M.L.L. 2009. Review of the areal extent and the volume of the Serra Geral Formation, Paraná Basin, South America. Pesq. Geoc., 36:49-57.

Gordon Jr. M. 1947. Classificação das formações gondwânicas do Paraná, Santa Catarina e Rio Grande do Sul. Notas Preliminares e Estudos, DNPM/DGM, 38:1-20.

Hebert L.B. \& Rossman G.R. 2008. Greenish quartz from the Thunder Bay amethyst mine Panorama, Thunder Bay, Ontario, Canada. Can. Mineral., 46:111-124.

Juchem P.L. 2013. O Distrito Mineiro de Ametista do Sulroteiro de excursão. In: UFSM, Seminário Brasileiro de Gemologia e Design de Joias, 3, p. 7-15.

Juchem P.L., Hofmeister T., Brum T.M.M. 1990. Substâncias gemológicas no Rio Grande do Sul modos de ocorrência e caracterização gemológica. In: SBG, Cong. Bras. Geol., 36, v. 3, p. 1436-1449.

Karfunkel J., Quéménéur J., Chaves M.L.S.C., Banko A.G., Lameiras F.S., Pinheiro M.V.B., Pfannes H.D., Krambrock K., Dantas M.S.S. 1998. A ametista de Grão Mogol (MG): ocorrência, descrição e métodos de tratamento. In: Cong. Bras. Geol., 40, Anais, p. 263. 
Knauer L.G., Pereira D.C., Guimaraes, F., Fantinel L.M., Costa, R.D. 2015. Geologia da Folha Mortugaba SD.23-Z-D-III. Belo Horizonte, CODEMIG, escala 1:100.000.

Lehmann G. \& Moore W.J. 1966. Color center in amethyst quartz. Science, 152:1061-1062.

Leonardos O.H. 1956. Recursos minerais do Triângulo Mineiro. Engenharia, Mineração e Metalurgia, 24:133-142.

London D. 2008. Pegmatites. Mineralogical Association of Canada, Québec, 347 p. (The Canadian Mineralogist, Special Publication 10).

Mattos L.E. 1974. Ágata no Brasil. In: Cong. Bras. Geol., 28, Anais, p. 249-259.

Moraes L.J. 1936. Quartzo no norte do Estado de Minas Gerais. Mineração e Metalurgia, 1(4):152-154.

Noce C.M. \& Fogaça A.C.C. 1997. Mapa geológico da Folha Curimataí SE.23-X-C-VI. Belo Horizonte, Projeto Espinhaço, COMIG/UFMG, escala 1:100.000.

Piccirillo E.M. \& Melfi A.J. (Coord.) 1988. The Mesozoic Flood Volcanism of the Paraná Basin: Petrogenetic and Geophysical Aspects. IAG-USP, São Paulo, 600 pp.

Pinheiro M.V.B. 1999. Investigação das alterações de cor em gemas do grupo do quartzo e sua correlação com as mudanças nos centros de cor induzidas por irradiação (X ou gama) e tratamentos térmicos. Belo Horizonte, Relatório de Projeto de Recém-Doutorado, CDTN, 43 p.

Pinto C.P. \& Silva M.A. 2014. Mapa Geológico do Estado de Minas Gerais. Belo Horizonte, Convênio CODEMIG/CPRM-SGB, escala 1:1.000.000.

Scholz R., Chaves M.L.S.C., Krambrock K., Pinheiro M.V.B., Barreto S.B., Menezes M.G. 2012. Brazilian Quartz Deposits with Special Emphasis on Gemstone Quartz and its Color Treatment. In: J. Götze \& R. Möckel (orgs.) Quartz: Deposits, Mineralogy and Analytics. New York: Springer-Verlag Berlin Heidelberg, v. 1, p.: 139-159.

Schultz-Güttler R.A. 2007. Quartzo verde ou prasiolita? Diamond News, 12:19-20.

Schumann W. 1995. Gemas do Mundo. 8a ed., Traduzido por R.R. Franco. Editora ao Livro Técnico, Rio de Janeiro, $254 \mathrm{pp}$.

Sgarbi G.N.C. 1997. Aspectos paleogeográficos e sedimentológicos do Mesozóico no Oeste do estado de Minas Gerais. Tese de Doutorado, Instituto de Geociências, Universidade de Brasília, 223 p.

Thiede D.S. \& Vasconcelos P.M. 2010. Paraná flood basalts: Rapid extrusion hypothesis confirmed by new 40Ar/39Ar results. Geology, 38:747-750.

Tupinambá M., Baars F.J., Uhlein A., Grossi-Sad J.H., Knauer L.G. 1996. Folha Rio Vermelho. Belo Horizonte, Projeto Espinhaço, Comig-UFMG, Mapa e Nota Explicativa.

Uhlein A. 1987. Geologia da Serra Negra, MG. Diamantina, Centro de Geologia Eschwege, Relatório de Auxílio à Pesquisa apresentado ao CNPq, 22 p.

Vieira V.S., Silva M.A., Corrêa T.R., Lopes N.H.B. 2013. Mapa geológico do Estado do Espírito Santo. Belo Horizonte, CPRM, escala 1:400.000. 